\title{
The Stability of Tailings Dams under Dry-Wet Cycles: A Case Study in Luonan, China
}

\author{
Xingang Wang ${ }^{1,2, *(\mathbb{D}}$, Hongbin Zhan ${ }^{3, *} \mathbb{D}$, Jiading Wang ${ }^{2}$ and Ping $\mathrm{Li}^{2}$ \\ 1 Key Laboratory of Mine Geological Hazards Mechanism and Control, Shaanxi Institute of \\ Geo-Environment Monitoring, Xi'an 710054, China \\ 2 State Key Laboratory of Continental Dynamics, Department of Geology, Northwest University, \\ Xi'an 710069, China; wangjd@nwu.edu.cn (J.W.); 20175080@nwu.edu.cn (P.L.) \\ 3 Department of Geology and Geophysics, Texas A\&M University, College Station, TX 77840, USA \\ * Correspondence: xgwang@nwu.edu.cn (X.W.); zhan@geos.tamu.edu (H.Z.)
}

Received: 12 July 2018; Accepted: 3 August 2018; Published: 7 August 2018

\begin{abstract}
Instability of tailings dams may result in loss of life and property and serious environmental pollution. The position of the tailings dam's phreatic line varies due to continuously changing factors such as rainfall infiltration and discharge of tailings recycling water. Consequently, tailings dams undergo dry-wet (DW) cycles, accompanied by the appearance of a hydro-fluctuation belt. With dynamic development of the physical and chemical properties of tailings sand in the hydro-fluctuation belt, the stability of tailings dams is uncertain. In this study, direct shear tests were performed on the tailings sand collected from a tailings dam in Luonan, through which the shear strength parameters of tailings sand with DW cycles were obtained. Then, a method that efficiently calculates the phreatic line of the tailings dam under DW cycles was proposed. In addition, based on laboratory tests and the proposed phreatic line calculation method, we used a finite element program to evaluate the stability of the tailings dam that experienced different DW cycles. The calculated results showed that: (i) the damage effects of DW cycles gradually weakens as the number of DW cycles increases. (ii) With the increasing of DW cycles, the maximum displacement of the tailings dam increases from $0.5 \mathrm{~mm}$ to $22 \mathrm{~mm}$, and the area of maximum displacement expanded mainly at the toe of the tailings dam and at the front edge of the hydro-fluctuation belt. (iii) The tailings dam safety factor decreases continuously with increasing DW cycles. This study may provide a novel method for analyzing the stability of tailings dams under different DW cycles as well as an important reference for improving tailings dam stability.
\end{abstract}

Keywords: dry-wet (DW) cycle; tailings dam; hydro-fluctuation belt; phreatic line; stability

\section{Introduction}

Tailings dams are formed as a result of the accumulation of dump slag from mining activities [1,2]. In China, there are more than 12,000 tailings dams and this number is still increasing [3,4]. Instability of tailings dams will result in loss of life and property and serious environmental pollution [5-7]. For example, 277 people died from the accident of the dam breaking at the tailings pond in Xiangfen County, China on 8 September 2008 [8].

The effect of water on the stability of tailings dams has been long recognized. For example, Blight (1997) [9] analyzed the effect of osmotic static force on the stability of tailings dams and reported that the wet ground surface of the tailings ponds could produce mudflows more easily than dry ground surfaces. More recently, Rico et al. [10] made a thorough investigation and evaluation of 147 known cases of tailings dam disasters around the world and concluded that water from sources such as extreme rainfall and inappropriate water discharge is considered as the most important factor that 
lead to instability of tailings dams. Furthermore, Zandarín et al. [1] studied the effect of capillary water in tailings dams and concluded that capillary action of water will reduce the tailings dam safety factor. Wickland et al. [11] investigated the hydraulic conductivity and consolidation response process of the mixtures of waste rock and tailings in the tailings pond and concluded that the mixing of waste rock and tailings sand can generate a high water storage rate, thus improving the stability of tailings pond.

Tailings dam stability analysis offers an efficient framework for systematic, logical incorporation of uncertainty into dam design. Extensive work has been done to develop tailings dam stability analysis methodologies. Lade and Yamamuro [12], for instance, analyzed the static liquefaction behavior of silt dams and then proposed a method for analyzing and evaluating silt dam slopes stability to predict potential liquefaction areas of slopes. Lei et al. [13], based on the seepage theory and the finite element strength reduction method, analyzed the stability of a three-dimensional tailings dams according to the parameters of cyclic triaxial strength and undrained triaxial compressive strength. More recently, Jin et al. [14] investigated the transport and deposition characteristics of suspended particles in porous media, and proposed a fluid-solid coupling model for a tailings dam with infiltration of suspended particles.

However, the operation of a tailings dam is a very complex process that involves numerous physical and chemical phenomena and intercoupling among these phenomena [1]. At present, there are few studies on the mechanical properties of tailings sand under dry-wet (DW) cycles. Moreover, little data were found to calculate the tailings dam phreatic line, which is significant in evaluating the stability of dam under DW cycles.

In this study, shear tests were conducted on tailings sand from Luonan County, China with different DW cycles. Then, the effect of DW cycles on tailings sand, which is affected by factors such as rainfall infiltration, tailings recycling water, and dry beach face evaporation, was simulated and the shear strength parameters of tailings sand under DW cycles were obtained at the same time. Additionally, a method for calculating the tailings dam phreatic line under DW cycles was proposed and combined with the laboratory results. Then, the stability of the tailings dam under different DW cycles was analyzed by using a finite element program.

\section{Engineering Overview and Test Results}

The tailings dam in this study is located in Luonan County, China (see Figure 1), at an altitude of $1392 \mathrm{~m} 1595 \mathrm{~m}$. The maximum vertical length and horizontal length of the tailings dam is approximately $286.2 \mathrm{~m}$ and $166 \mathrm{~m}$. Since a residential area, a highway, and a river are located downstream, instability of the tailings dam is a great hazard. A geological survey designated to evaluate the stability of the tailings dam was conducted, and samples were collected from the rear edge of the dam crest (see Figure 1b). After transporting the samples to the laboratory, the FDJ-20 unsaturated soil direct shear instrument (see Figure 2) was used to conduct shear tests under different DW cycles. Vertical pressures varying from $50 \mathrm{kPa}$ to $300 \mathrm{kPa}$ were applied in the present study. The test results are shown in Table 1.

Table 1. Shear strength of tailings sand after dry-wet (DW) cycles.

\begin{tabular}{|c|c|c|c|c|c|c|}
\hline \multirow{2}{*}{$\begin{array}{l}\text { Number of } \\
\text { Cycles }\end{array}$} & \multicolumn{4}{|c|}{ Shear Strength under Different Vertical Pressures } & \multirow{2}{*}{$\begin{array}{l}\text { Cohesion } c \\
\quad(\mathbf{k P a})\end{array}$} & \multirow{2}{*}{$\begin{array}{c}\text { Angle of Shearing } \\
\text { Resistance } \ddot{y}\left({ }^{\circ}\right)\end{array}$} \\
\hline & $50 \mathrm{kPa}$ & $100 \mathrm{kPa}$ & $200 \mathrm{kPa}$ & $300 \mathrm{kPa}$ & & \\
\hline 1 & 21.31 & 50.52 & 82.88 & 122.62 & 5.82 & 21.35 \\
\hline 2 & 21.67 & 37.10 & 65.66 & 102.20 & 4.85 & 17.68 \\
\hline 3 & 20.15 & 36.68 & 61.46 & 97.86 & 4.68 & 16.89 \\
\hline 4 & 19.42 & 36.54 & 58.24 & 95.76 & 4.54 & 16.44 \\
\hline 5 & 18.39 & 36.26 & 60.48 & 94.92 & 4.11 & 15.58 \\
\hline 6 & 17.34 & 32.05 & 58.10 & 90.72 & 4.08 & 15.38 \\
\hline
\end{tabular}




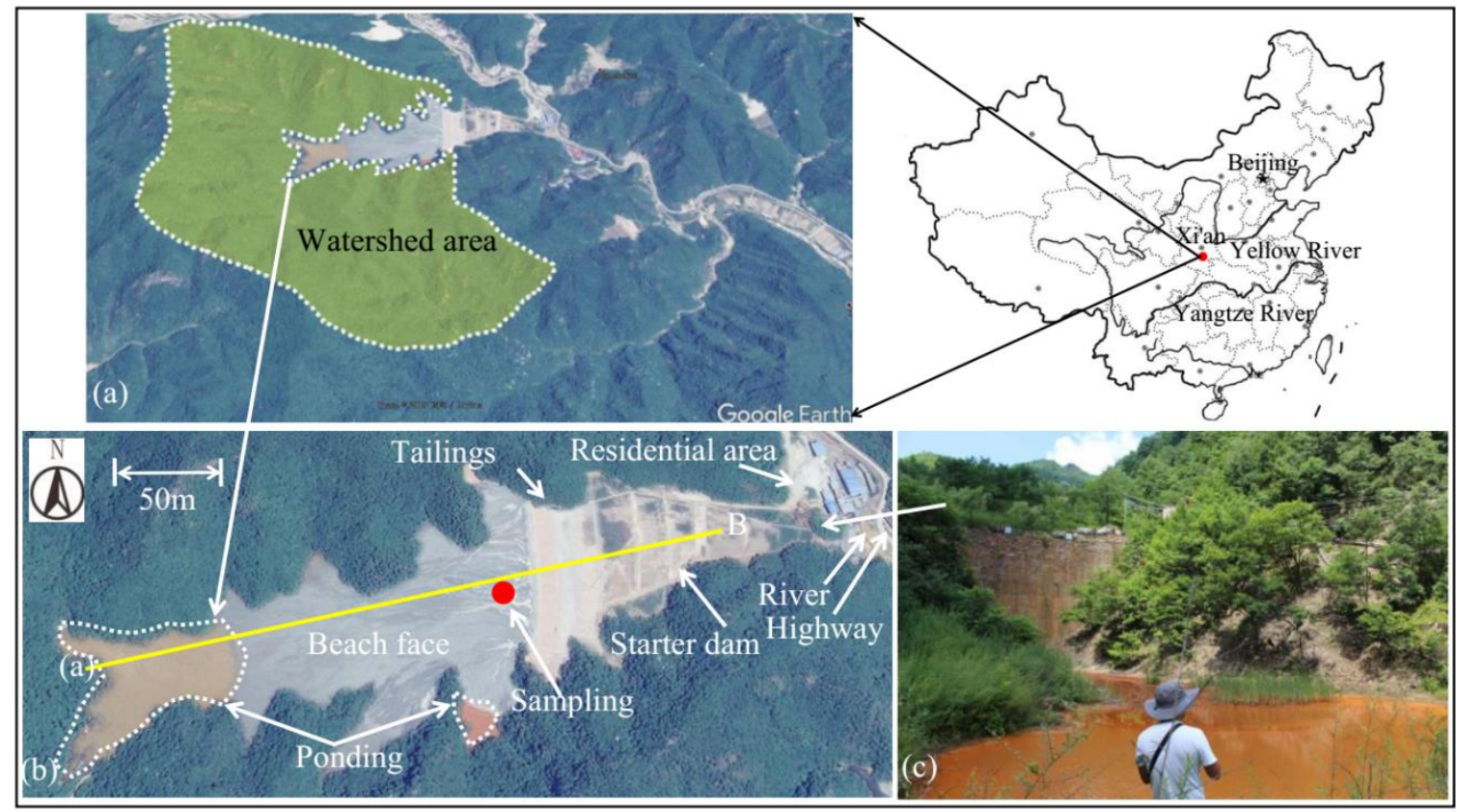

Figure 1. Location of the tailings dam. (a) Watershed area; (b) Sampling point; (c) Downstream of the dam.

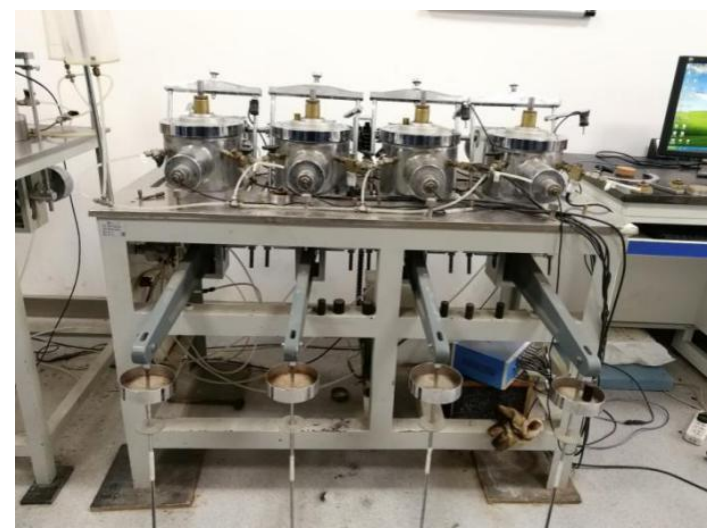

(a)

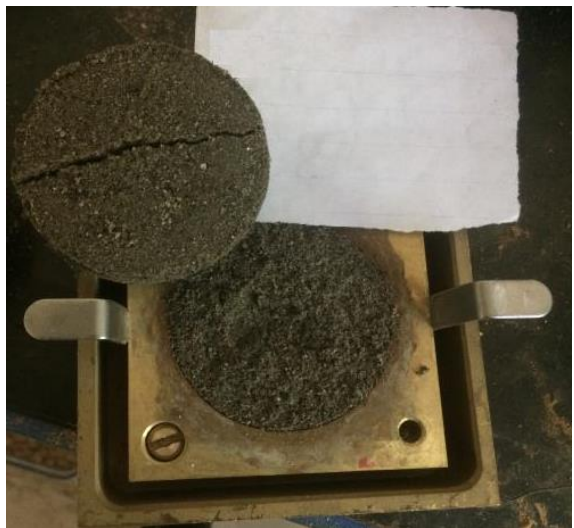

(b)

Figure 2. FDJ-20 soil direct shear instrument and the shear failure surface after shearing (a) Direct shear apparatus; (b) Shear failure surface after shearing.

Table 1 shows that the cohesion and angle of shearing resistance of soil reduce non-linearly with the dry-wet cycles. Based on the results in Table 1, the determined cohesion as well as frictional angle is plotted in Figure 3 against the corresponding dry-wet cycles. By fitting the data in Figure 3, the relationships between the cohesion as well as frictional angle with the dry-wet cycles are expressed as follows:

$$
c=3.02 \times \exp (-n / 1.85)+4, \varphi=13 \times \exp (-n / 1.22)+15.52
$$

It is obvious from the fitting curves that cohesion and angle of shearing resistance reduce exponentially with the increse of dry-wet cycles, and the correlation coefficients of the fitting data for cohesion and angle of shearing resistance are 0.96 and 0.98 , respectively. 


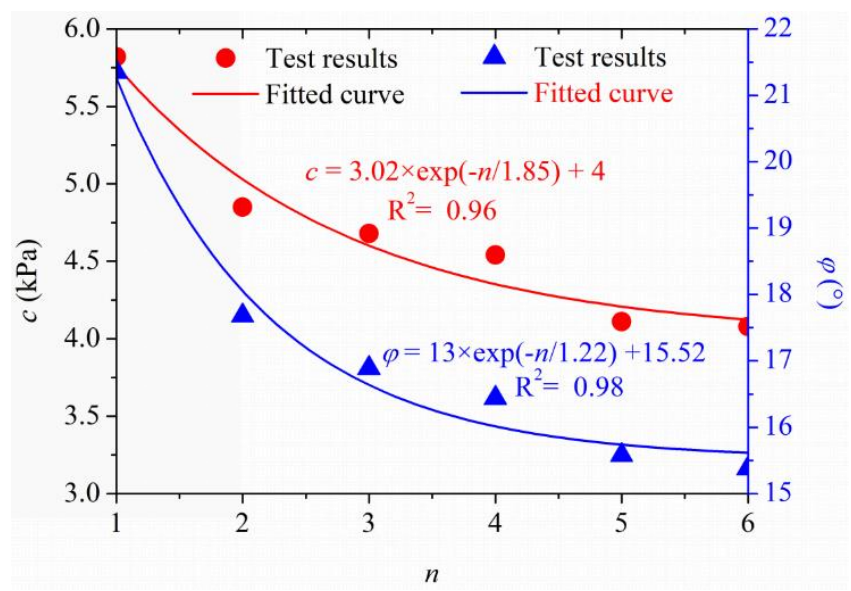

Figure 3. Relationships between cohesion and angle of shearing resistance with dry-wet cycles. Note: $c=$ cohesion, $\varphi=$ angle of shearing resistance, $n=$ numbers of dry-wet cycles.

\section{Methods for Calculating and Modeling the Tailings Dam's Phreatic Line under DW Cycles}

\subsection{Method for Calculating the Tailings Dam's Phreatic Line under DW Cycles}

Numerical analysis has been widely used to solve complex issues about the slope stability of tailings dams $[4,15,16]$. Affected by rainfall infiltration, tailings recycling water, dry beach face evaporation, and other factors, the position of the phreatic line in the tailings pond suffers in various ways in the DW cycles $[1,17,18]$. Therefore, in the numerical analysis mode, the determination of the position of the phreatic line under DW cycles plays an important role [19-27]. Figure 4 shows the diagram for calculating the tailings dam's phreatic line.

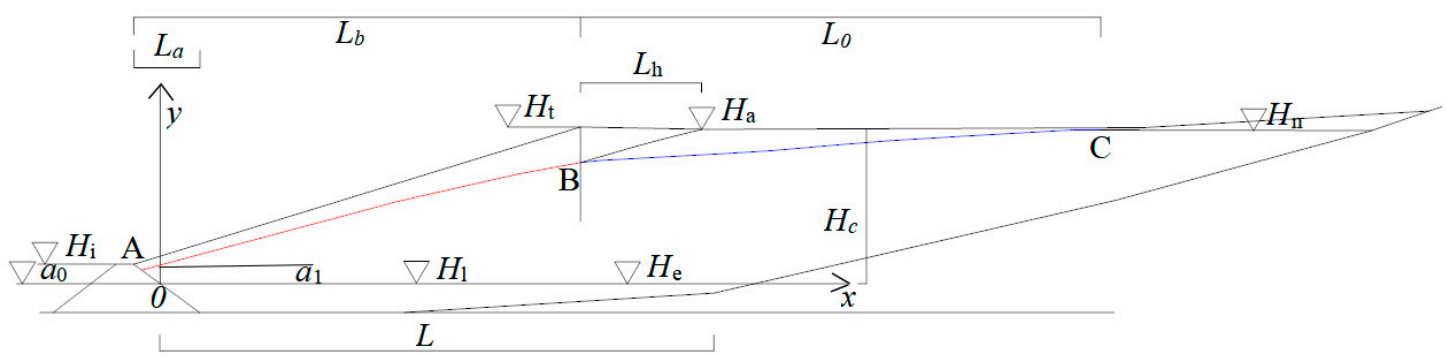

Figure 4. Diagram for calculating the tailings dam's phreatic line. $H_{\mathrm{i}}$ is the starter dam elevation; $H_{\mathrm{t}}$ is the tailings dam elevation; $H_{\mathrm{n}}$ is the normal reservoir water level; $H_{\mathrm{a}}$ is the corrected amendatory reservoir water level; $H_{\mathrm{e}}$ is the water inlet elevation; $H_{\mathrm{l}}$ is the long-term eliminating seepage elevation; $H_{\mathrm{c}}$ is the calculated water head; $L$ is the seepage length; $L_{a}$ is the upstream projected length of the started dam; $L_{b}$ is the distance between the starter dam and the tailings dam; $L_{0}$ is the length of dry beach face; $L_{\mathrm{h}}$ is the corrected length of dry beach face; $a_{0}$ is the water overflow height; $a_{1}$ is the intercept of the phreatic line on the y-axis; $\mathrm{A}, \mathrm{B}$, and $\mathrm{C}$ is the intersection of the curve at the corresponding position in the graph.

As illustrated in the Chinese Standard Safety Technical Regulations for the Tailing Pond (AQ2006-2005) [28], the tailings dam's phreatic line is calculated as follows:

$$
L_{\mathrm{h}}=3.3 \times L_{0}^{0.48}
$$


where $L_{\mathrm{h}}$ is the value when the dry beach face is mostly covered by tailings water (i.e., when the phreatic line is in a "wet" state).

$$
H_{\mathrm{a}}=H_{\mathrm{t}}-L_{\mathrm{h}} \times \theta
$$

where $\theta$ is the slope of dry beach face;

$$
\begin{gathered}
H_{\mathrm{c}}=H_{\mathrm{a}}-H_{1} \\
L=L_{\mathrm{b}}-L_{\mathrm{a}}+L_{\mathrm{h}} \\
a_{0}=a_{1} / 2 \sqrt{1+m^{2}}-L
\end{gathered}
$$

where $m$ is the upstream slope ratio.

$$
a_{1}=\sqrt{H_{c}^{2}+L^{2}}-L
$$

In Figure 4, the equation for segment $\mathrm{AB}$ (red curve) of the phreatic line is expressed as

$$
y=\sqrt{a_{1}^{2}+2 a_{1} x}
$$

The equation for segment BC (blue curve from Figure 4) of the phreatic line of is expressed as

$$
y=\log _{\beta}^{x}
$$

Here, $\beta$ value can be obtained from the two equations and the coordinates of the point of intersection between the two curves. The phreatic line can be calculated by combining Equations (2)-(9) when the tailings dam is in a "wet" state.

After discharge of mine water (recycling water) and rainfall evaporation, the value in Equation (2) when a small area of dry beach face is covered (i.e., when the phreatic line is in a "dry" state) changes to [29]:

$$
L_{\mathrm{h}}=2.26 \times L_{0}^{0.645}
$$

The phreatic line equation varies with the change of $L_{\mathrm{h}}$ value. Therefore, if we substitute Equation (10) into Equations (3)-(9), we get the phreatic line when the tailings dam is in a "dry" state.

Equations (2)-(10) are formulas to calculate the tailings dam's phreatic line under DW cycles.

\subsection{Numerical Model for the Tailings Dam under DW Cycles}

Finite element numerical analysis method, of which the reliability has been verified, has been widely used in the stability analysis of tailings slope $[3,4,14]$. According to a field survey of the tailings dam shown in Figure 1, a finite element numerical model was established for the A- $\mathrm{A}^{\prime}$ profile in Figure $1 \mathrm{~b}$, and a mesh element was generated and is shown in Figure 5 . The numerical model is $75 \mathrm{~m}$ in height and $286.2 \mathrm{~m}$ in length. The mesh consists of 6456 triangles and 13,208 nodes. It is important to point out that two phreatic lines in the blue zone were calculated from the method presented in Section 3.1. The positions data of two phreatic lines were imported into numerical model, and then the two lines shaped a hydro-fluctuation belt with a certain area [23], which is shown in the water blue area in Figure 5.

The left boundary of the model is vertically constrained, while the bottom boundary is fully constrained. The strength reduction method developed by Dawson et al. [30] was applied to calculate the tailings dam's safety factor in this study. Previous research reported that the effect of the geotechnical parameters such as the modulus of elasticity and the Poisson's ratio of sandy soil on the dam stability is negligible when using the finite element strength reduction method to calculate the dam safety factor $[4,31]$. Hence, in the simulations performed in this study, parameters for the materials in the numerical model were assigned based on field survey data and routine geotechnical tests of tailings sand, which are shown in Table 2. The angle of shearing resistance and the cohesion of 
tailings sand in the hydro-fluctuation belt under different DW cycles were assigned according to data in Table 1.

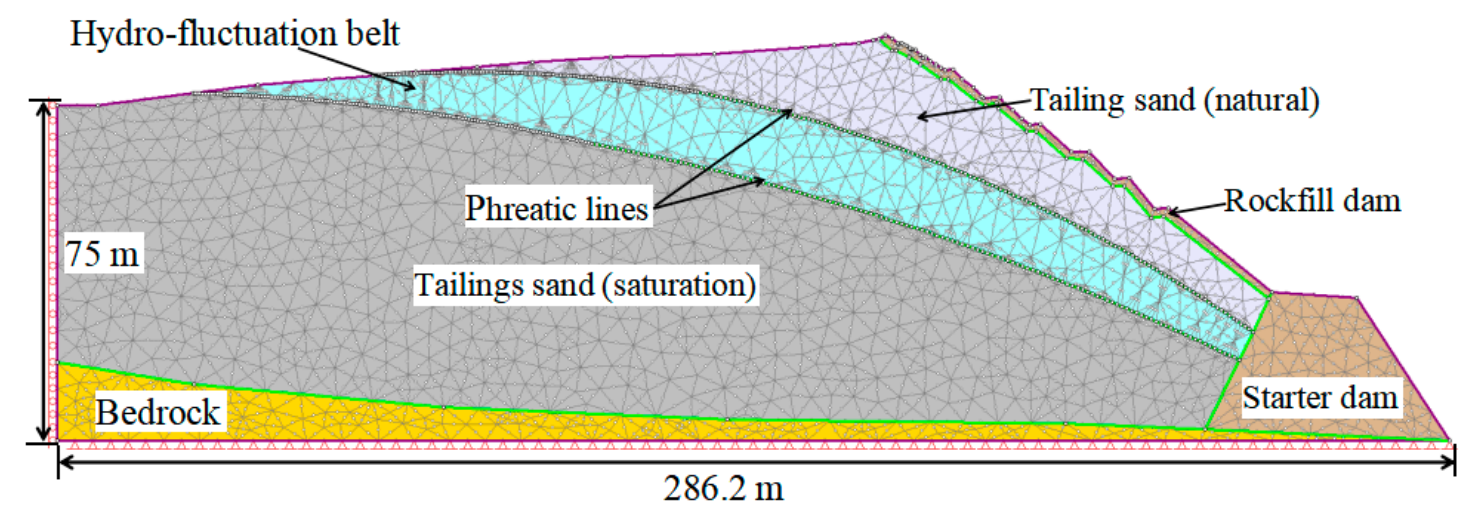

Figure 5. Numerical calculation model.

Table 2. Calculation parameters for the numerical model.

\begin{tabular}{ccccccc}
\hline Lithology & $\boldsymbol{\rho}\left(\mathbf{k N} / \mathbf{m}^{\mathbf{3}}\right)$ & $\boldsymbol{E} \mathbf{( M P a})$ & $\boldsymbol{\mu}$ & $\boldsymbol{\tau} \mathbf{( M P a})$ & $\boldsymbol{\varphi}\left({ }^{\circ}\right)$ & $\boldsymbol{c} \mathbf{( k P a )}$ \\
\hline Tailings sand (natural) & 15.3 & 30 & 0.35 & $/$ & 30.25 & 7.04 \\
Tailings sand (saturation) & 17.9 & 28 & 0.36 & $/$ & 28.74 & 6.69 \\
Rockfill dam & 19.5 & 860 & 0.2 & 2.0 & 35.00 & 125 \\
Starter dam & 22.5 & 1532 & 0.3 & 3.0 & 38.00 & 300 \\
Bedrock & 24.4 & 34,884 & 0.25 & 3.9 & 44.03 & 37,413 \\
\hline
\end{tabular}

Note: $\rho$ is density; $E$ is Young's modulus; $\mu$ is Poisson's ratio; $\tau$ is Tensile strength; $\varphi$ is angle of shearing resistance; $c$ is Cohesion.

\section{Results and Discussion}

The Mohr-Coulomb criterion was chosen as the constitutive model for materials shown in Figure 5. Moreover, data in Tables 1 and 2 were substituted into the finite element program for calculation. After different dry-wet cycles, the maximum shear stress, maximum displacement, and safety factor are shown in Table 3.

Table 3. Tailings dam calculated results after DW cycles.

\begin{tabular}{cccc}
\hline $\begin{array}{c}\text { Number of DW } \\
\text { Cycles }\end{array}$ & $\begin{array}{c}\text { The Maximum Shear } \\
\text { Stress (MPa) }\end{array}$ & $\begin{array}{c}\text { The Maximum } \\
\text { Displacement } \mathbf{( m m})\end{array}$ & Safety Factor \\
\hline 1 & 0.56 & 0.5 & 1.84 \\
2 & 1.43 & 12 & 1.52 \\
3 & 1.75 & 16 & 1.46 \\
4 & 1.96 & 19 & 1.41 \\
5 & 2.07 & 21 & 1.37 \\
6 & 2.11 & 22 & 1.33 \\
\hline
\end{tabular}

In order to get insight into the results in Table 3, the calculated results including shear stress, displacement, and safety factor were analyzed and are discussed in the following sections.

\subsection{Analysis of Shear Stress Contour}

The shear stress contour is one of the criteria for judging the sliding surface caused by instability of the tailings dam, and the area where the sliding surface is located is often the area where the value of shear stress changes significantly [15]. The shear stress of the numerical calculation model in Figure 5 after six DW cycles is shown in Figure 6. 

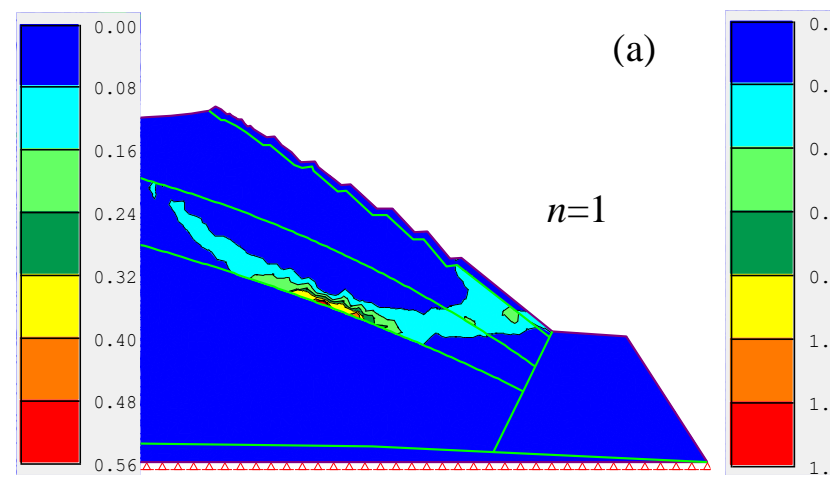

(b)
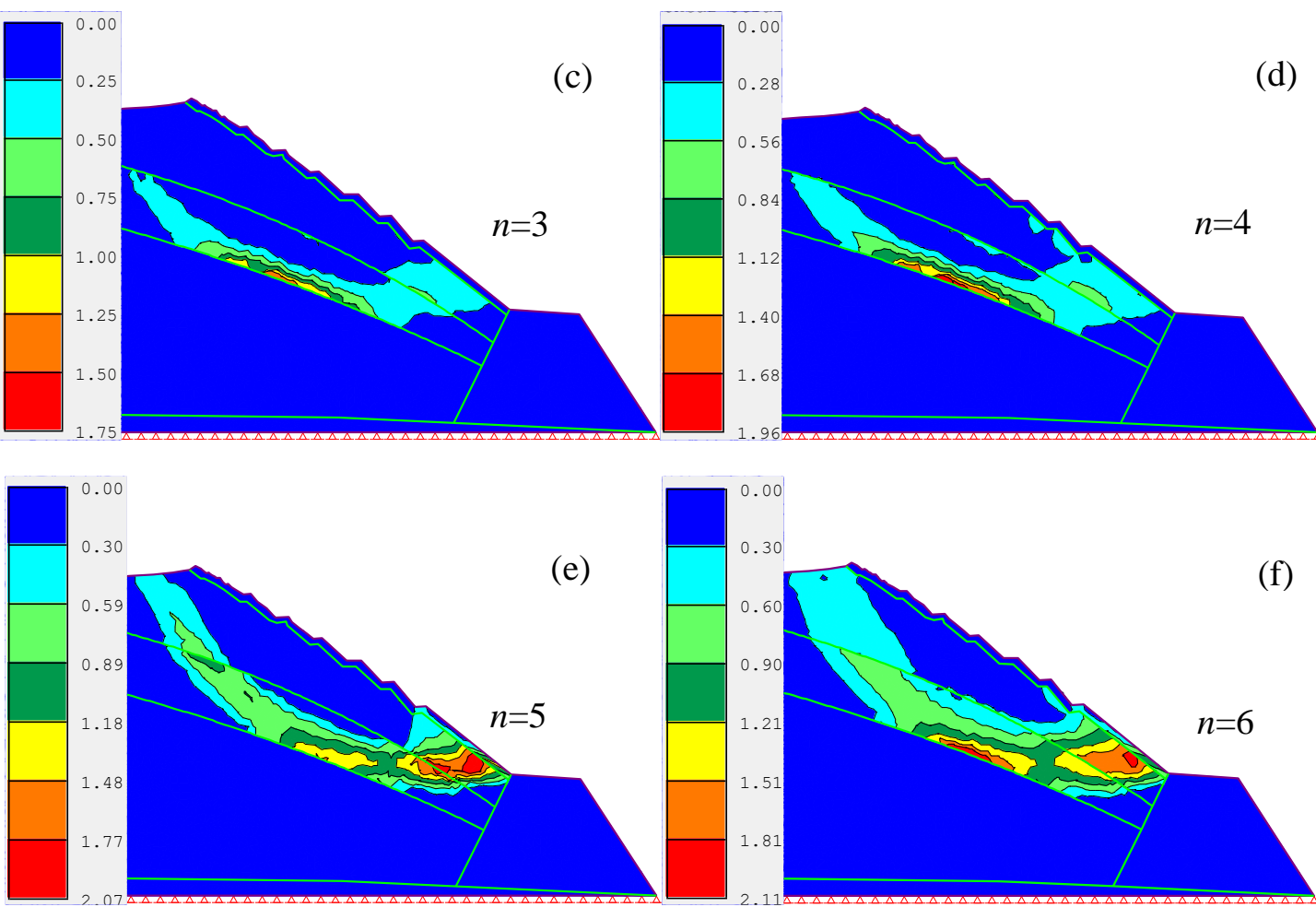

Figure 6. Diagram of shear stress after different DW cycles ( $n$ is the number of DW cycles). (a) $n=1$; (b) $n=2 ;$ (c) $n=3 ;$ (d) $n=4 ;(\mathbf{e}) n=5 ;(\mathbf{f}) n=5$.

As shown in Figure 6a, after one DW cycle, local shear stress concentration was found at the front edge of the hydro-fluctuation belt and at the toe of the tailings dam, with the maximum shear stress of $0.56 \mathrm{MPa}$. After 2, 3, and $4 \mathrm{DW}$ cycles, the area of shear stress concentration gradually expanded, with a continuous shear stress concentration zone in the hydro-fluctuation zone (see Figure $6 \mathrm{~b}-\mathrm{d}$ ). At that moment, the corresponding values of maximum shear stress for 2,3, and 4 DW cycles were $1.43,1.75$, and $1.96 \mathrm{MPa}$, respectively. After 5 and $6 \mathrm{DW}$ cycles, the shear stress distribution gradually developed to the top of dry beach surface, accompanied by a potential sliding surface (see Figure $6 \mathrm{e}, \mathrm{f}$ ). At that moment, the values of maximum shear stress were 2.07 and $2.11 \mathrm{MPa}$, respectively for 5 and $6 \mathrm{DW}$ cycles. It was observed that the maximum shear stress is mainly concentrated at the front edge of the hydro-fluctuation belt and at the toe of the tailings dam. Moreover, the maximum shear stress after $2 \mathrm{DW}$ cycles was 2.55 times of that after $1 \mathrm{DW}$ cycle. As the number of DW cycles increases, the difference in the maximum shear stress of adjacent cycles decreases. 


\subsection{Analysis of Displacement}

The displacement of the numerical model in Figure 5 after 6 DW cycles is shown in Figure 7.
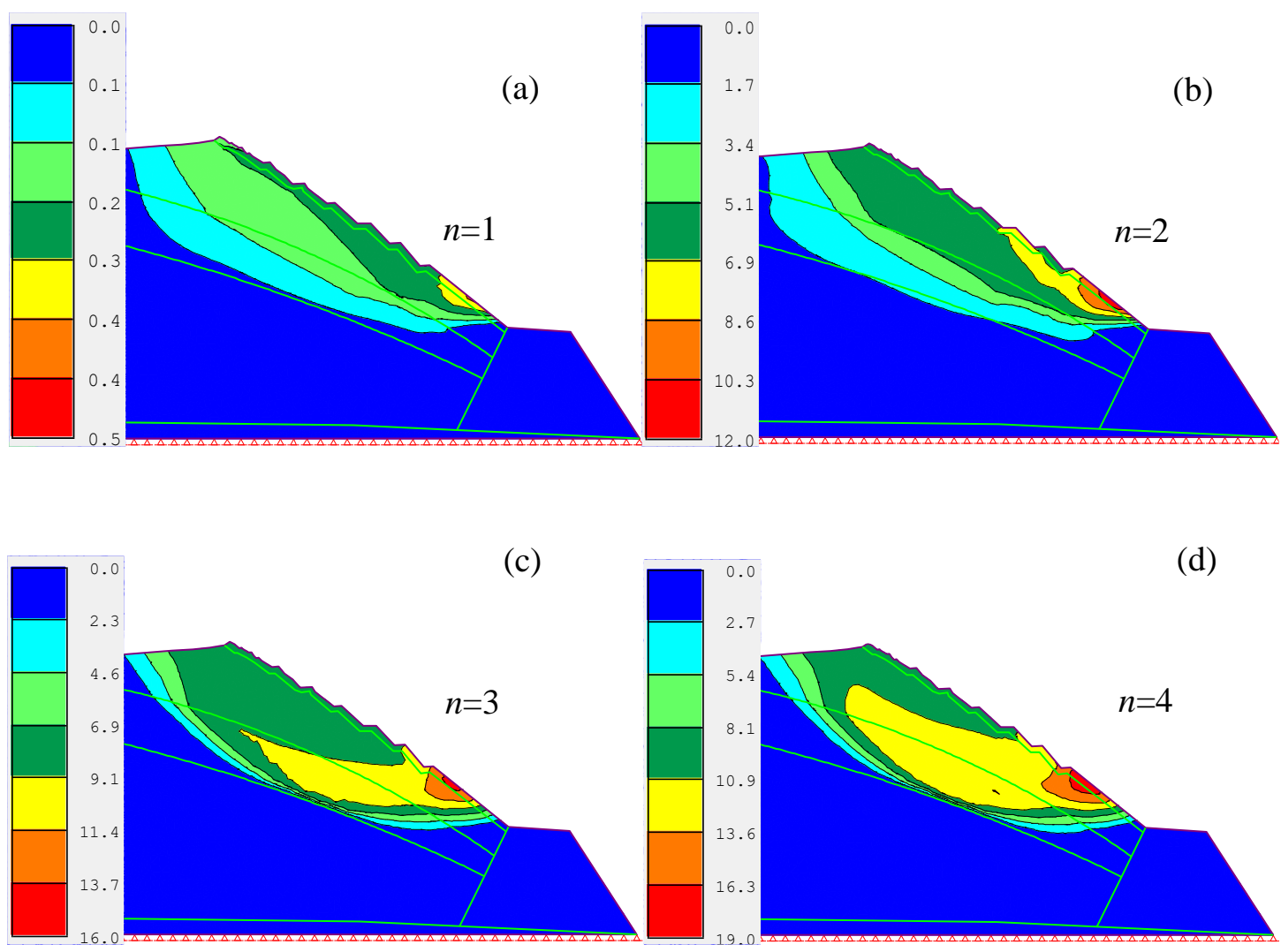

(d)

(e)

(f)
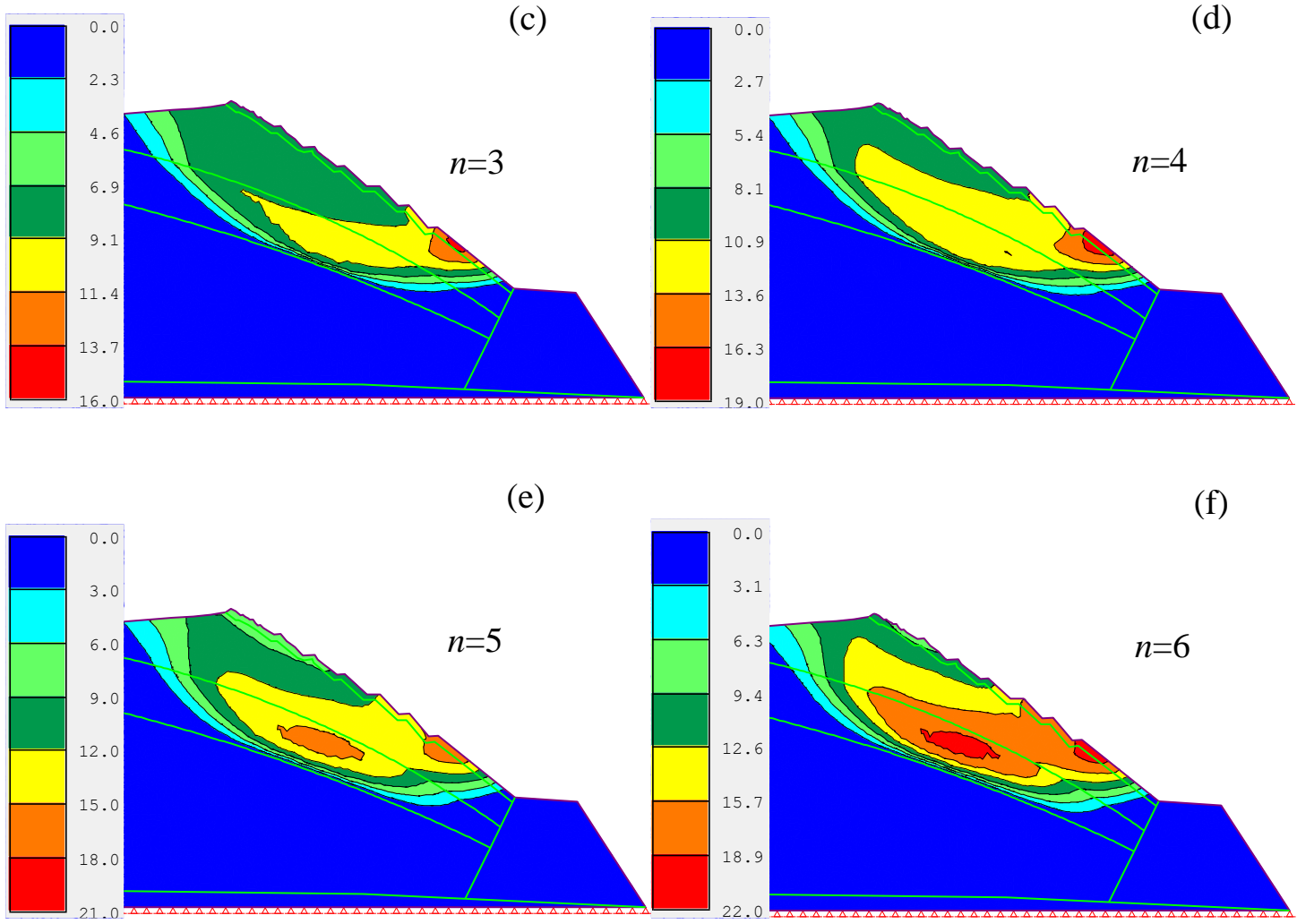

Figure 7. Diagram of displacement after different DW cycles ( $n$ is the number of DW cycles). (a) $n=1$; (b) $n=2 ;$ (c) $n=3 ;$ (d) $n=4 ;(\mathbf{e}) n=5 ;$ (f) $n=5$.

As illustrated in Figure 7a, after 1 DW cycle, the maximum displacement of the model reached $0.5 \mathrm{~mm}$ at the toe of the tailings dam. After 2,3, and 4 cycles, the maximum displacement increased to $12 \mathrm{~mm}, 16 \mathrm{~mm}$, and $19 \mathrm{~mm}$, respectively. It is clear that the maximum displacement occurred at the toe of the tailings dam. Furthermore, the area of maximum displacement gradually enlarged as the number of DW cycle increased (see Figure 7b-d). Additionally, after 5 and 6 DW cycles, the maximum displacement was $21 \mathrm{~mm}$ at the toe of tailings dam and $22 \mathrm{~mm}$ at the front edge of the hydro-fluctuation belt (see Figure 7e,f). After 6 DW cycles, the area of maximum displacement was large and the area of maximum displacement in the hydro-fluctuation belt zone was relatively continuous (see Figure 7f). 


\subsection{Analysis of Safety Factor}

The proposed approach consists of five major steps to determine the safety factor of tailings dam:

(i) As revealed by Lei et al. [11], the strength reduction factor $F_{\mathrm{s}}$ is assumed, the cohesion $c$ and the angle of shearing resistance $\varphi$ on the sliding surface are reduced as follows:

$$
c_{e}=c / F_{\mathrm{s}}, \tan \varphi_{e}=\tan \varphi / F_{\mathrm{s}}
$$

where $c_{e}$ and $\varphi_{e}$ are respectively the cohesion and the angle of shearing resistance after reduction.

(ii) Based on the elastoplastic theory, apply boundary condition and material parameters to determine the stress and deformation of the tailings dam.

(iii) For elements on the sliding surface, the sliding resistance $F_{\mathrm{r}}$ and the sliding force $F_{\mathrm{t}}$ are calculated as follows [30]:

$$
F_{\mathrm{r}}=\frac{1}{t} \sum_{i=1}^{N_{\mathrm{e}}} \sum_{g=1}^{N_{\mathrm{g}}}\left(-\tan \varphi_{\mathrm{ei}} \sigma_{\text {nig }}+c_{\mathrm{ei}}\right) v_{i g} F_{\mathrm{r}}=\frac{1}{t} \sum_{i=1}^{N_{\mathrm{e}}} \sum_{g=1}^{N_{\mathrm{g}}}\left|\tau_{\text {nig }}\right| v_{i g}
$$

where $N_{\mathrm{e}}$ is the number of elements; $N_{\mathrm{g}}$ is the number of Gaussian integration points in each element; $\sigma_{\text {nig }}$ is the normal stress at the $g$ th Gaussian point in the $i$ th element; $\tau_{\text {nig }}$ is the shear stress at the $g$ th Gaussian point in the $i$ th element; $v_{\text {ig }}$ is the control volume at the $g$ th Gaussian point in the $i$ th element; $t$ is the calculated thickness of elements on the sliding surface; $c_{\mathrm{ei}}$ is the reduced cohesion; and $\varphi_{\mathrm{ei}}$ is the reduced angle of shearing resistance.

(iv) Calculate the new safety factor $F_{\mathrm{s}}{ }^{*}$ by Equation (11).

$$
F_{\mathrm{s}}^{*}=F_{\mathrm{s}} \sum_{e=1}^{N_{\mathrm{e}}} F_{\mathrm{r}} / \sum_{e=1}^{N_{\mathrm{e}}} F_{\mathrm{t}}
$$

(v) Judge the convergence

$$
\frac{\left|F_{\mathrm{s}}^{*}-F_{\mathrm{s}}\right|}{F_{\mathrm{s}}^{*}} \leq \text { Assigned error }
$$

The calculation is considered finished when Equation (14) is satisfied and the safety factor is determined as $F_{s}^{*}$. Otherwise, the calculation should be repeated according to Equations (11) and (12) until the results meet the Equation (14). Based on the safety factor calculation equations (Equations (11)-(14)) contained in the finite element software, calculation was performed for the model in Figure 5. Then, the tailings dam safety factors after different DW cycles were obtained and shown in Table 3.

As listed in Table 3, the tailings dam safety factor decreased continuously with the DW cycle. Moreover, it is obvious that the safety factor decreased significantly from 1 DW cycle to 2 DW cycles, while the difference in safety factor between adjacent DW cycles became small after $2 \mathrm{DW}$ cycle. The results suggest the first and second DW cycles reduce the stability of the tailings dam remarkably.

\section{Conclusions}

In the present study, a direct shear test and finite element numerical calculations were conducted on sands collected from a tailings dam in Luonan, China. The following conclusions can be drawn:

(i) A method that efficiently calculates the phreatic line of the tailings dam under DW cycles was developed. It is capable of obtaining the boundaries of the hydro-fluctuation belt of the tailings dam under DW cycles so that the results of laboratory tests under DW cycles can be applied in numerical simulation and calculation in practical engineering. 
(ii) The maximum shear stress of the tailings dam after two DW cycles was 2.55 times that after one DW cycle. However, as the number of DW cycle increases, the difference in maximum shear stress decreases, accompanied by the weakened damage effect of DW cycles. After 5 and 6 DW cycles, the shear stress distribution gradually extends to the top of dry beach surface, with a potential sliding surface developed.

(iii) With increasing DW cycles, the maximum displacement of the tailings dam increased from $0.5 \mathrm{~mm}$ to $22 \mathrm{~mm}$, and the area of maximum displacement expanded mainly at the toe of the tailings dam and at the front edge of the hydro-fluctuation belt. Moreover, the corresponding safety factor of tailings dam after each cycle nonlinearly reduced, and DW cycles strongly affected the safety of the tailings dam, especially after 1 and 2 DW cycles.

(iv) In the numerical simulation of this study, the tailings sand under DW cycles was identified as in fully saturated condition, without considering unsaturated tailings sand that is prevalent in real engineering. Therefore, our future study should take the boundaries between saturated and unsaturated tailings sand into account so as to calculate the tailings dam stability more realistically.

Author Contributions: X.W. designed the experiments, analyzed data, and wrote the whole paper; H.Z. guided the writing of the article and revised the article; J.W. designed the experiments and helped to select experimental area; P.L. analyzed data.

Funding: The research is supported by two funds, namely (1) the Open Fund Project of Key Laboratory of Mine Geological Hazards Mechanism and Control (No. KF2017-03) and (2) the National Natural Science Foundation of China (No. 41630639).

Conflicts of Interest: The authors declare no conflict of interest.

\section{References}

1. Zandarín, M.T.; Oldecop, L.A.; Rodríguez, R.; Zabala, F. The role of capillary water in the stability of tailing dams. Eng. Geol. 2009, 105, 108-118. [CrossRef]

2. Liu, H.; Yang, C.; Zhang, C.; Mao, H. Study on static and dynamic strength characteristics of tailings silty sand and its engineering application. Saf. Sci. 2012, 50, 828-834. [CrossRef]

3. Xu, B.; Wang, Y. Stability Analysis of the Lingshan Gold Mine Tailings Dam under Conditions of a Raised Dam Height; Bulletin of Engineering Geology and the Environment; Springer: Basel, Switzerland, 2015; Volume 74, pp. 151-161.

4. Yin, G.; Li, G.; Wei, Z.; Wan, L.; Shui, G.; Jing, X. Stability analysis of a copper tailings dam via laboratory model tests: A Chinese case study. Miner. Eng. 2011, 24, 122-130. [CrossRef]

5. Rico, M.; Benito, G.; Díez-Herrero, A. Floods from tailings dam failures. J. Hazard. Mater. 2008, 154, 79-87. [CrossRef] [PubMed]

6. Saad, B.; Mitri, H. Hydromechanical analysis of upstream tailings disposal facilities. J. Geotech. Geoenviron. Eng. 2011, 137, 27-42. [CrossRef]

7. Wei, Z.; Yin, G.; Li, G.; Wang, J.G.; Wan, L.; Shen, L. Reinforced terraced fields method for fine tailings disposal. Miner. Eng. 2009, 22, 1053-1059. [CrossRef]

8. Wei, Z.; Yin, G.; Wang, J.G.; Wan, L.; Li, G. Design, construction and management of tailings storage facilities for surface disposal in China: Case studies of failures. Waste Manag. Res. 2013, 31, 106-112. [CrossRef] [PubMed]

9. Blight, G.E. Destructive mudflows as a consequence of tailings dyke failures. Proc. Inst. Civ. Eng. Geotech. Eng. 1997, 125, 9-18. [CrossRef]

10. Rico, M.; Benito, G.; Salgueiro, A.R.; Díez-Herrero, A.; Pereira, H.G. Reported tailings dam failures: A review of the european incidents in the worldwide context. J. Hazard. Mater. 2008, 152, 846-852. [CrossRef] [PubMed]

11. Wickland, B.E.; Wilson, G.W.; Wijewickreme, D. Hydraulic conductivity and consolidation response of mixtures of mine waste rock and tailings. Can. Geotech. J. 2010, 47, 472-485. [CrossRef]

12. Lade, P.V.; Yamamuro, J.A. Evaluation of static liquefaction potential of silty sand slopes. Can. Geotech. J. 2011, 48, 247-264. [CrossRef] 
13. Lei, B.; Zhou, H.; Li, C. Three-dimensional stability analysis of fine grained tailings dam with complex terrain by means of up-stream method. Electron. J. Geotech. Eng. 2016, 21, 3905-3918.

14. Jin, J.; Song, C.; Chen, Y. Investigation of a fluid-solid coupling model for a tailings dam with infiltration of suspended particles. Environ. Earth Sci. 2017, 76, 758. [CrossRef]

15. Ormann, L.; Zardari, M.A.; Mattsson, H.; Bjelkevik, A.; Knutsson, S. Numerical analysis of strengthening by rockfill embankments on an upstream tailings dam. Can. Geotech. J. 2013, 50, 391-399. [CrossRef]

16. Poulad, D.; Zsaki, A.M. Simulation of tailings flow resulting from a dam breach using smoothed particle hydrodynamics. Environ. Eng. Geosci. 2018, 12, 1-17.

17. Al-Tarhouni, M.; Simms, P.; Sivathayalan, S. Cyclic behaviour of reconstituted and desiccated-rewet thickened gold tailings in simple shear. Can. Geotech. J. 2011, 48, 1044-1060. [CrossRef]

18. Lu, C.; Wu, Y.; Hu, S. Drying-wetting cycles facilitated mobilization and transport of metal-rich colloidal particles from exposed mine tailing into soil in a gold mining region along the Silk Road. Environ. Earth Sci. 2016, 75, 1031. [CrossRef]

19. Dong, L.; Shu, W.; Sun, D.; Li, X.; Zhang, L. Pre-alarm system based on real-time monitoring and numerical simulation using internet of things and cloud computing for tailings dam in mines. IEEE Access 2017, 5, 21080-21089. [CrossRef]

20. Dong, L.; Sun, D.; Li, X. Theoretical and case studies of interval nonprobabilistic reliability for tailing dam stability. Geofluids 2017, 5, 18804-18817. [CrossRef]

21. Pan, J.; Song, Y.; Zeng, Q.; Zhu, H. Influence factors analysis of seismic liquefaction risk for tailings dam. Electron. J. Geotech. Eng. 2015, 20, 4167-4180.

22. Ridolfi, E.; Manciola, P. Water level measurements from drones: A pilot case study at a dam site. Water 2018, 10, 297. [CrossRef]

23. Wang, X.; Wang, J.; Gu, T.; Lian, B. A modified hoek-brown failure criterion considering the damage to reservoir bank slope rocks under water saturation-dehydration circulation. J. Mt. Sci. 2017, 14, 771-781. [CrossRef]

24. Sun, G.; Zheng, H.; Huang, Y.; Li, C. Parameter inversion and deformation mechanism of Sanmendong landslide in the Three Gorges Reservoir region under the combined effect of reservoir water level fluctuation and rainfall. Eng. Geol. 2016, 205, 133-145. [CrossRef]

25. Sun, G.; Yang, Y.; Cheng, S.; Zheng, H. Phreatic line calculation and stability analysis of slopes under the combined effect of reservoir water level fluctuations and rainfall. Can. Geotech. J. 2017, 54, 631-645. [CrossRef]

26. Conte, E.; Troncone, A. A performance-based method for the design of drainage trenches used to stabilize slopes. Eng. Geol. 2018, 239, 158-166. [CrossRef]

27. Conte, E.; Donato, A.; Pugliese, L.; Troncone, A. Analysis of the Maierato landslide (Calabria, Southern Italy). Landslides 2018. [CrossRef]

28. SAWSC. Safety Technical Regulations for the Tailings Pond; State Administration of Work Safety of China: Beijing, China, 2006.

29. Li, L.; Chu, X. Study on the effect of phreatic line depth on the evaluation of slope stability for tailing dam. J. Saf. Sci. Technol. 2011, 11, 003.

30. Dawson, E.M.; Roth, W.H.; Drescher, A. Slope stability analysis by strength reduction. Geotechnique 1999, 49, 835-840. [CrossRef]

31. Coulibaly, Y.; Belem, T.; Cheng, L. Numerical analysis and geophysical monitoring for stability assessment of the Northwest tailings dam at Westwood Mine. Int. J. Min. Sci. Technol. 2017, 27, 701-710. [CrossRef]

(C) 2018 by the authors. Licensee MDPI, Basel, Switzerland. This article is an open access article distributed under the terms and conditions of the Creative Commons Attribution (CC BY) license (http:// creativecommons.org/licenses/by/4.0/). 